\section{Social functioning and the course}

of early-onset schizophrenia

\author{
Five-year follow-up of a psychosocial intervention \\ MARIE E. LENIOR, PETER M. A. J. DINGEMANS, DON H. LINSZEN, \\ LIEUWE DE HAAN and AART H. SCHENE
}

\begin{abstract}
Background Schizophrenia implies severe social impairments. Since the treatment of patients with schizophrenia shifted from long-term hospital admissions to community services, research on social functioning has become increasingly important.
\end{abstract}

Aims Follow-up assessment of social functioning in young patients with schizophrenia during a 5-year period after intervention.

Method During intervention, families were randomised into two conditions: standard intervention and standard plus family intervention.

Results Although no differential treatment effect with regard to the course of the illness was found, patients from the standard plus family intervention condition stayed for fewer months in institutions for psychiatric patients than patients from the standard intervention condition.

Conclusions Family intervention has helped parents to support their children, thereby diminishing institutional care.

Declaration of interest This study was funded by grants $28-124 \mid-I$ and 28-124I-2 from the Dutch Health Research and Development Council and by the Dutch Ministry of Welfare, Health and Cultural Affairs (Project 90-120; CRO 50458I).
For many years research on schizophrenia was focused on psychotic symptoms (Strauss, 1975; Engelhardt \& Rosen, 1976). However, schizophrenia implies severe psychosocial limitations. For this reason social functioning as an outcome measure in psychiatric research has gained attention. Engelhardt \& Rosen (1976) remarked that psychosocial handicaps are the most severe consequences of schizophrenia. Strauss \& Carpenter (1974) noted that in research on the course of schizophrenic illness, social functioning is an important outcome measure. In this follow-up study we describe aspects of social functioning and the course of psychotic symptoms in young patients with early-onset schizophrenia and related disorders 5 years after intervention. The differential effect of two intervention conditions on social functioning and the course of the illness is evaluated. Finally, we investigate the association between social functioning and severity of the illness (e.g. diagnostic grouping and the course of the illness).

\section{METHOD}

\section{Subjects}

This study concerns the 5-year follow-up of a 15-month intervention in the Adolescent Clinic of the Psychiatric Department of the Academic Medical Center in Amsterdam. Before the controlled trial began, families were stratified into high and low expressed emotion (Vaughn \& Leff, 1976) and randomised into two conditions: standard intervention or standard plus behavioural family intervention. The intervention programme and the two intervention conditions are described in detail elsewhere (Linszen et al, 1996). Briefly, the programme consisted of a 3-month in-patient phase and an outpatient phase of 12 months. Family intervention consisted of supporting parents, and psychoeducation, training in communication skills and problem-solving techniques with families. After discharge, patients were referred to psychiatric services in their area of residence.

Of the 97 families who formerly underwent the intervention programme, 73 participated in the follow-up study, after giving written informed consent. Reasons for non-participation were: refusal (4), not traceable (10), emigration (1) and fatal accident (1). Furthermore, eight patients committed suicide: three (14\%) from the group that was not randomised (see Linszen et al, 1996); two (5\%) from families that received family intervention; and three $(8 \%)$ from the standard intervention.

Data were available in 58 cases from the patient and one or two parents, and in 13 cases from one or two parents but without the patient. Two patients participated without their parent(s). On average, the interviews took place 7.9 (range 6-10) years after discharge.

The mean age of the patients (51 men and 22 women) at admission was 20.9 (range 16-26) years (Table 1), whereas the mean age at the time of the follow-up interview was 30.5 (range 26-37) years. The mean duration of untreated illness before admission was 5.4 months and half of the patients (52\%) had their first psychotic episode before admission. At discharge from the intervention programme, the diagnoses (DSM-III-R; American Psychiatric Association, 1987) were: schizophrenia, 42 (58\%); schizoaffective disorder, 15 (21\%); schizophreniform disorder, 9 (12\%); and other psychotic disorders (e.g. delusional disorder and atypical psychosis), $7(10 \%)$.

Comparisons between participating patients and non-participants of the followup study showed that at admission participants were 1 year older on average than non-participants, that the duration of untreated psychosis was 1 month less on average and that compliance to medication during intervention was higher for participants than for non-participants. Regarding baseline data, no significant differences between the two intervention conditions were found.

\section{Assessments}

Patients and parents were interviewed with the Life Chart Schedule (LCS: World Health Organization, 1992). This instrument elicits data about symptoms, treatment (rehospitalisation, living in sheltered homes, out-patient treatment) and social conditions (employment, study, living 
Table I Demographic and psychiatric characteristics of participants and non-participants

\begin{tabular}{|c|c|c|c|c|c|c|c|c|}
\hline & \multicolumn{2}{|c|}{$\begin{array}{l}\text { All subjects } \\
\quad(n=97)\end{array}$} & \multicolumn{2}{|c|}{$\begin{array}{c}\text { Non-participants } \\
(n=24)\end{array}$} & \multicolumn{2}{|c|}{$\begin{array}{l}\text { Participants } \\
\quad(n=73)\end{array}$} & \multicolumn{2}{|c|}{$\begin{array}{l}\text { Test non-participants } \\
\text { v. participants }\end{array}$} \\
\hline & & & & & & & Statistic & $P$ \\
\hline Age at admission, mean (s.d.) & 20.5 & $(2.5)$ & 19.5 & $(2.6)$ & 20.9 & $(2.4)$ & 624 & 0.03 \\
\hline \multicolumn{9}{|l|}{ Gender, $n$ (\%) } \\
\hline Female & 26 & (27) & 4 & (17) & 22 & (30) & 1.67 & 0.20 \\
\hline Male & 71 & (73) & 20 & (83) & 51 & $(70)$ & & \\
\hline \multicolumn{9}{|l|}{ Education, $n$ (\%) } \\
\hline$<$ Secondary school & 21 & (22) & 6 & (25) & 15 & $(2 I)$ & 0.21 & 0.65 \\
\hline$\geqslant$ Secondary school & 76 & (78) & 18 & (75) & 58 & $(80)$ & & \\
\hline \multicolumn{9}{|l|}{ Socio-economic status, $n$ (\%) } \\
\hline Low (III-V) & 73 & (75) & 20 & (83) & 53 & (73) & 1.12 & 0.29 \\
\hline High (I-II) & 24 & $(25)$ & 4 & (17) & 20 & $(27)$ & & \\
\hline Age of onset of schizophrenia, mean (s.d.) & 19.1 & $(2.6)$ & 18.5 & $(2.8)$ & 19.3 & $(2.5)$ & 759 & 0.32 \\
\hline \multicolumn{9}{|l|}{ Prior psychotic episodes, $\boldsymbol{n}(\%)$} \\
\hline None & 55 & (57) & 17 & (7I) & 38 & (52) & 2.59 & 0.11 \\
\hline One or more & 42 & $(43)$ & 7 & (29) & 35 & $(48)$ & & \\
\hline \multicolumn{9}{|l|}{ Prior admissions, $n$ (\%) } \\
\hline None & 57 & (59) & 18 & (75) & 39 & (53) & 3.47 & 0.06 \\
\hline One or more & 40 & $(4 I)$ & 6 & (25) & 34 & $(47)$ & & \\
\hline \multicolumn{9}{|l|}{ DSM-III-R schizophrenia, $n$ (\%) } \\
\hline No & 41 & $(42)$ & 10 & $(42)$ & 31 & $(42)$ & $<0.01$ & 0.95 \\
\hline Yes & 56 & (58) & 14 & (58) & 42 & (58) & & \\
\hline Months of untreated illness, mean (s.d.) & 5.6 & $(10.2)$ & 6.3 & $(6.1)$ & 5.4 & $($ (II.2) & 589 & 0.05 \\
\hline Sum score of positive and negative symptoms, ${ }^{2}$ mean (s.d.) & 15.1 & $(4.7)$ & 15.6 & (3.4) & 14.9 & $(5.0)$ & 730 & 0.22 \\
\hline Compliance with antipsychotic medication, ${ }^{3}$ mean (s.d.) & 3.7 & $(0.7)$ & 3.4 & $(1.0)$ & 3.8 & $(0.4)$ & 665 & 0.04 \\
\hline
\end{tabular}

I. For categorical variables the statistic is $\chi^{2}$ (d.f.=l); for continuous variables the statistic is $U$ (Mann-Whitney test, two-tailed).

2. Positive symptoms: unusual thought content, hallucinatory behaviour, conceptual disorganisation, distractability; negative symptoms: motor retardation, blunted affect, emotional withdrawal (Breier et al, 199l). Items were scored from I (not present) to 7 (very severe). The mean item scores of the previous 2 months of in-patient treatment were used.

3. Mean compliance during in-patient and out-patient treatment was used. Compliance was scored from I (no compliance: $0 \%$ ) to 4 (I00\% compliance, including depot).

arrangements) during a given period. Susser et al (2000) showed that the LCS yields reliable ratings of the long-term course of schizophrenia when assessed by trained raters. Inconsistencies regarding symptoms and treatment $(n=3)$ were cross-checked with current therapists.

The first follow-up study, which also included the LCS, was carried out in 1992. At that time the follow-up period differed for the successively admitted and discharged patients (17-55 months). At the second follow-up, held in 1997-1998, the data were completed up to and including 5 years after discharge. If the patient and/or parent(s) had participated in 1992, which was the case for all but one patient, the data of that interview were first examined and completed for the 5 -year period.

The course of the illness was divided into psychotic and non-psychotic episodes. A psychotic episode was characterised by clearly reported positive symptoms, i.e. delusions, hallucinations and/or formal thought disorders (Nuechterlein et al, 1986). A non-psychotic episode was a period without positive symptoms, with or without residual symptoms and/or negative symptoms. A non-psychotic episode had to last at least 30 days (Wiersma et al, 1998). When there was never a 30-day remission period during follow-up, the patient was considered as having chronic positive symptoms (60 months).

The LCS data were first rated for relapses by one of the authors (D.H.L.) and rated again by a psychiatrist (L.d.H.), who was employed 2 years after the intervention and had not been involved with the patients. Regarding clinical status (no relapse, one or more relapses, chronic), there was disagreement about six patients $(8 \%)$. For $16(22 \%)$ patients the number of months with psychotic symptoms differed (mean absolute difference $=6.7$; s.d.=6.8). For the 22 patients about whom there was disagreement, consensus was achieved by re-examination of the data by both raters together.

\section{Analyses}

For analyses concerning social functioning, three composite scores were calculated: living in institutions for psychiatric patients (months in mental hospitals and/or sheltered homes); structural activities (months of fulltime, part-time or voluntary work, full-time study and/or housekeeping); help from the family (sum score of help with activities of daily living, accompanying to out-patient services, checking intake of medication and management of care). The four items concerning help from the family were scored as follows: 1, 'none'; 2, 'part of period'; 3, 'majority of period' (Table 2).

The duration of psychotic episodes is an important indicator of the severity of the illness. Therefore the course of the illness 
was expressed as the number of months that patients had psychotic symptoms. For chronic patients this was 60 months.

Mann-Whitney U-tests were used to compare the three areas of social functioning by intervention condition and by diagnosis group (schizophrenia $v$. schizophrenia-like disorder) as classified at discharge. Testing associations between the three areas of social functioning and the total duration of psychotic episodes was done by Spearman's rank correlations $(\rho)$.

\section{RESULTS}

On average, patients lived within the community for 42 of the 60 months (Table 2). Of the patients, $40 \%$ lived alone for the major part of the 5 -year period; $34 \%$ lived for the most part with parent(s); $12 \%$ lived with a partner; $7 \%$ lived otherwise (not in institutions for psychiatric patients); and $7 \%$ lived for the total 5 -year period in institutions for psychiatric patients. Seven patients were homeless for some days $(n=3)$ or some months $(n=4)$, meaning that they had no steady place of residence during that period, or that their place of residence was unknown. One patient stayed in prison for 1 month.

Of the patients, 34 held a paid job for at least some period. For these patients the occupational level in $65 \%$ of the cases was lower than their level of education: in $62 \%$ of the cases, unskilled or semi-skilled jobs. For $74 \%$ of the patients who held a paid job, the performance of their work was qualified as 'good' to 'very good' by patient and/or parent(s). This qualification is related to the level of the work (e.g. working in shops, catering, warehouses, light office jobs). Six patients did the housekeeping full-time during some period of the 5 years. For only one of them was the performance in housekeeping qualified as 'poor'. In the 5-year period 21 patients followed full-time study for some of the time. The mean number of months during which patients had structural activities was 26.2 (s.d. $=20.0$; range $=0-60$ ). This implies that they had no structural activities for almost 3 years (34 months).

As mentioned, five patients stayed in institutions for psychiatric patients for 60 months. The patient group stayed for 8 months on average in mental hospitals and for 10 months in sheltered homes. The mean number of months that patients
Table 2 Socio-demographic characteristics according to the Life Chart Schedule (World Health Organization, 1992) during the 60-month follow-up period $(n=73)$

\begin{tabular}{|c|c|c|c|}
\hline Item & Category & Mean (n) & s.d. (\%) \\
\hline \multicolumn{4}{|l|}{ Living arrangements } \\
\hline \multicolumn{2}{|l|}{ Months within the community } & 41.8 & 20.0 \\
\hline \multirow[t]{2}{*}{ With parents' } & No & 43 & 63 \\
\hline & Yes & 25 & 37 \\
\hline \multicolumn{4}{|l|}{ Work } \\
\hline \multirow[t]{2}{*}{ Paid jobs } & Never & 39 & 53 \\
\hline & Some period & 34 & 47 \\
\hline \multicolumn{2}{|l|}{ Months of full-time jobs } & 5.2 & 12.8 \\
\hline \multicolumn{2}{|l|}{ Months of part-time jobs } & 4.8 & 9.6 \\
\hline \multirow[t]{3}{*}{ Performance in jobs held ${ }^{2}$} & Poor & 9 & 26 \\
\hline & Good & 17 & 50 \\
\hline & Very good & 8 & 24 \\
\hline \multirow[t]{3}{*}{ Type of usual job ${ }^{2}$} & Unskilled & 7 & 21 \\
\hline & Semi-skilled & 14 & 41 \\
\hline & Skilled & 13 & 38 \\
\hline \multirow[t]{3}{*}{ Level of usual job ${ }^{2}$} & Much lower & 6 & 18 \\
\hline & Lower & 16 & 47 \\
\hline & About the same & 12 & 35 \\
\hline \multicolumn{2}{|l|}{ Months of full-time housekeeping ${ }^{3}$} & 2.1 & 8.9 \\
\hline \multirow[t]{3}{*}{ Global score for work/housekeeping ${ }^{4}$} & Poor & 17 & 25 \\
\hline & Fair & 36 & 52 \\
\hline & Good & 16 & 23 \\
\hline \multicolumn{2}{|l|}{ Months of voluntary work } & 7.6 & 11.7 \\
\hline \multicolumn{2}{|l|}{ Months of full-time study } & 6.7 & I5.I \\
\hline \multicolumn{2}{|l|}{ Months of receiving disability pension } & 40.2 & 25.9 \\
\hline \multicolumn{2}{|l|}{ Months unemployed } & 6.8 & 15.8 \\
\hline \multicolumn{4}{|l|}{ Follow-up treatment } \\
\hline \multicolumn{2}{|l|}{ Months in mental hospital } & 7.8 & 11.6 \\
\hline \multicolumn{2}{|l|}{ Number of hospital admissions } & 1.4 & 1.7 \\
\hline \multicolumn{2}{|l|}{ Duration of longest admission (months) } & 5.5 & 9.0 \\
\hline \multicolumn{2}{|l|}{ Months in sheltered homes } & 9.5 & 16.7 \\
\hline \multirow[t]{2}{*}{ Day treatment } & Never & 41 & 56 \\
\hline & Some period & 32 & 44 \\
\hline Out-patient services & Never & 17 & 23 \\
\hline & Some period & 56 & 77 \\
\hline Family therapy & Never & 64 & 88 \\
\hline & Some period & 9 & 12 \\
\hline Help from the family & & & \\
\hline Daily activities & None & 23 & 32 \\
\hline & Part of period & 27 & 37 \\
\hline & Majority of period & 23 & 32 \\
\hline Accompanying for out-patient services & None & 41 & 56 \\
\hline & Part of period & 24 & 33 \\
\hline & Majority of period & 8 & II \\
\hline Checking medication compliance & None & 48 & 66 \\
\hline & Part of period & 19 & 26 \\
\hline & Majority of period & 6 & 8 \\
\hline Management of care & None & 46 & 63 \\
\hline & Part of period & 14 & 19 \\
\hline & Majority of period & 13 & 18 \\
\hline
\end{tabular}

I. Five patients never lived outside institutions for psychiatric patients.

2. Thirty-nine patients never held a paid job.

3. In the sense of caring for a family member.

4. Four patients never had a paid job and never lived outside institutions for psychiatric patients. 
stayed in institutions for psychiatric patients was 17.3 (s.d.=19.4; range $=0-60$ ).

During follow-up, patients required some help from their families, mainly parents. Of the patients, $69 \%$ received help with the performance of daily activities, mainly housekeeping, almost half of them $(32 \%)$ during the major part of the 5-year period. Almost half of the patient group (44\%) was accompanied by parent(s) when having an appointment for out-patient services. Many parents $(34 \%)$ checked medication compliance. Finally, it appeared that in $37 \%$ of the cases the parents helped the patient with seeking help or making decisions about treatment. The mean sum score for help from the family was 6.5 (s.d.=2.2; range $=4-12$ ).

A quarter of the patients $(n=19)$ did not have a psychotic episode during follow-up, half of them $(n=36)$ had one or more episodes and a quarter $(n=18)$ had chronic positive symptoms. In the 55 non-chronic cases, the relapse rate was $42 \%$ after 2 years and $65 \%$ after 5 years (Fig. 1). If we include chronic cases, $26 \%$ did not have a relapse in the 5 -year period. For all patients the mean total duration of psychotic episodes was 19.2 (s.d. $=24.5$; range $=0-60$ ) months.

Intervention condition had no effect on psychotic episodes (Table 3). Patients at discharge who had a diagnosis of schizophrenia had 14 more months of psychotic symptoms, on average, than patients with other diagnoses. This is related to the fact that the 42 patients with a diagnosis of schizophrenia more often had a chronic course than the 31 patients with a schizophrenia-like disorder (33\% v. 13\%; $\chi^{2}=4.01$; d.f. $=1 ; P=0.05$ ).

For structural activities and help from the family, no significant differences were found between intervention conditions (Table 4). For patients who received additional family intervention, the number of months spent in institutions for psychiatric patients was 10 months less, on average, than for patients from the standard condition.

Comparisons between diagnostic subgroups (Table 4) reveal that patients with a diagnosis of schizophrenia spent almost 9 months longer in institutions for psychiatric patients than patients with other diagnoses. They also received more help from their families. For structural activities the difference was not significant.

Correlations between total duration of psychotic episodes and the three areas of social functioning indicate that patients with a longer duration of psychotic symptoms

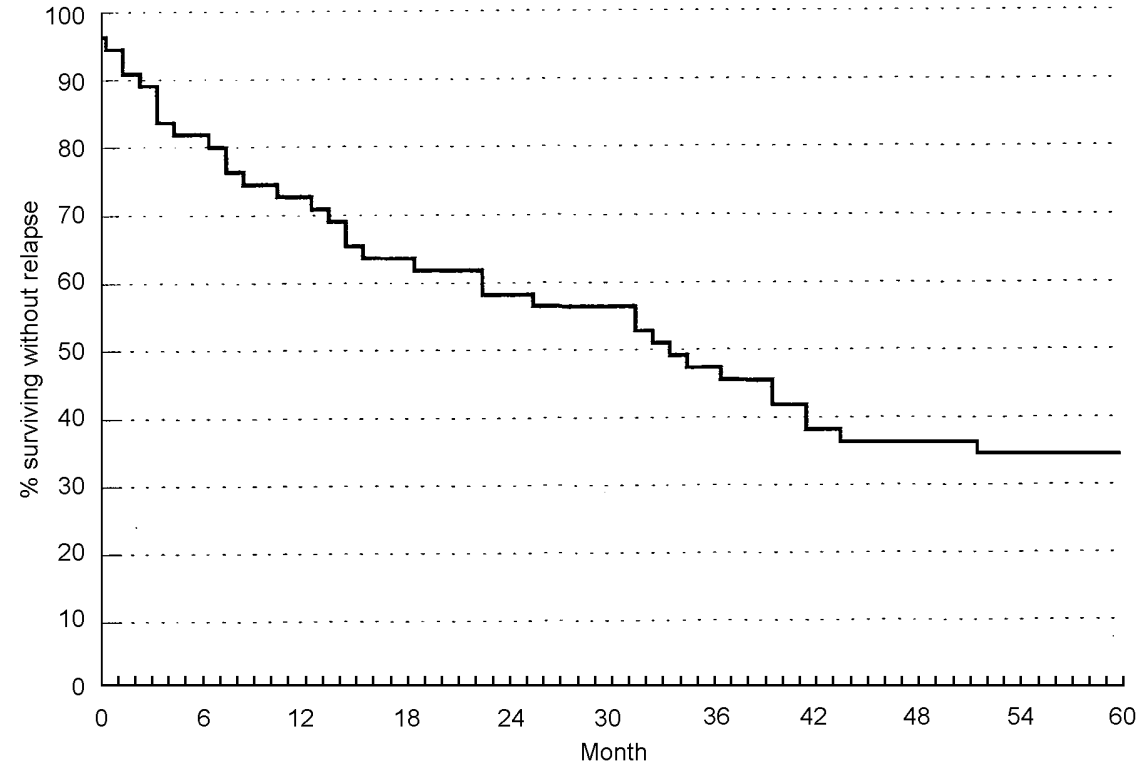

Fig. I Kaplan-Meier curve of relapses of patients without chronic positive symptoms $(n=55)$.

Table 3 Total duration of psychotic episodes (in months) during 60 months of follow-up by intervention condition and by diagnostic group $(n=73)$

\begin{tabular}{llllll}
\hline & $n$ & Mean & s.d. & $U^{\prime}$ & $P$ \\
\hline $\begin{array}{l}\text { Intervention condition } \\
\quad \text { Standard }\end{array}$ & 33 & 18.82 & 24.29 & 470 & 0.57 \\
$\quad$ Standard+family & 31 & 16.35 & 23.15 & & \\
Schizophrenia & & & & \\
No & & & & & \\
Yes & 31 & 11.23 & 19.77 & 431 & 0.01 \\
\hline
\end{tabular}

I. Mann-Whitney test, two-tailed.

2. Nine families were not randomised: three families ceased the treatment in an early phase; three families refused the expressed-emotion assessment and could not be randomised; three families refused randomisation.

3. DSM-III-R, as classified at discharge from the intervention.

spent longer in institutions for psychiatric patients $(\rho=0.30 ; P=0.01)$, had shorter periods of structural activities $(\rho=-0.34$; $P=0.003)$ and received more help from their families $(\rho=0.38 ; P=0.001)$ than patients with a shorter duration of psychotic symptoms.

\section{DISCUSSION}

\section{Social functioning and course of illness}

The results show patients with schizophrenia or a schizophrenia-like disorder to have considerable social limitations. For the young adults in our study parents appear to play an important role in supporting their offspring, in activities of daily living as well as in matters of follow-up treatment. Structural activities were rather scarce in this patient group: patients had no structural activities for almost 3 of the 5 years. This indicates that more attention should be paid to opportunities to activate and to support individuals who stay in the community to find structural activities, whether paid or unpaid. Voluntary, unpaid work appears to be an important activity. The number of months that this type of work was done was higher than the number of months in paid jobs. Voluntary jobs are important, because they give patients a feeling of worth and raise their sense of accomplishment. They also offer patients the opportunity to structure their life.

An earlier study (Linszen et al, 1996) showed that relapses could be delayed during intervention: $16 \%$ of the patients relapsed during the 12-month out-patient phase of the intervention. The results of the present study show that this beneficial 
Table 4 Social functioning during 60 months of follow-up by intervention condition and by diagnostic group $(n=73)$

\begin{tabular}{|c|c|c|c|c|c|c|c|c|c|c|c|c|c|}
\hline & \multicolumn{5}{|c|}{$\begin{array}{l}\text { Living in institutions for psychiatric } \\
\text { patients (months) }\end{array}$} & \multicolumn{4}{|c|}{$\begin{array}{l}\text { Structural activities } \\
\text { (months) }\end{array}$} & \multicolumn{4}{|c|}{$\begin{array}{l}\text { Help from the family } \\
\text { (sum score) }\end{array}$} \\
\hline & $n$ & Mean & s.d. & $U^{\prime}$ & $P$ & Mean & s.d. & $U^{\prime}$ & $P$ & Mean & s.d. & $U^{\prime}$ & $P$ \\
\hline \multicolumn{14}{|c|}{ Intervention condition ${ }^{2}$} \\
\hline Standard & 33 & 21.18 & 20.34 & 363 & 0.04 & 21.94 & 18.70 & 408 & 0.16 & 6.48 & 2.12 & 504 & 0.92 \\
\hline Standard+family & 31 & 10.87 & 16.15 & & & 28.84 & 19.96 & & & 6.45 & 2.16 & & \\
\hline \multicolumn{14}{|l|}{ Schizophrenia ${ }^{3}$} \\
\hline No & 31 & 12.13 & 15.76 & 479 & 0.05 & 28.65 & 19.47 & 553 & 0.27 & 5.84 & 1.86 & 456 & 0.03 \\
\hline Yes & 42 & 21.07 & 21.10 & & & 24.45 & 20.40 & & & 7.02 & 2.32 & & \\
\hline
\end{tabular}

I. Mann-Whitney test, two-tailed.

2. Nine families were not randomised: three families ceased the treatment in an early phase; three families refused the expressed-emotion assessment and could not be randomised; three families refused randomisation.

3. DSM-III-R, as classified at discharge from the intervention.

effect did not last. After 2 years, $42 \%$ of the patients had a relapse. In a review, Mari $\&$ Streiner (1994) reported relapse rates of $47-53 \%$ within 2 years. In another study with Dutch patients (Wiersma et al, 1998) the relapse rate after 5 years was $72 \%$, which is higher than our relapse rate (65\%). Robinson et al (1999) found a higher relapse rate of $82 \%$. Thus, the relapse rate in our study is still lower than in other studies. However, the results of the present study are congruent with the observation of McGlashan \& Johannessen (1996) that interventions are effective as long as they are active.

\section{Effect of family intervention}

Patients who had received additional family intervention spent fewer months in institutions for psychiatric patients than patients who had had the standard intervention. Falloon et al (1982), Tarrier et al (1989) and Xiong et al (1994) also found this effect, in combination with a differential effect on the occurrence of relapses. Falloon et al (1982) suggested that the reduction of stress in families who received family intervention prevented relapses and rehospitalisation. Our results do not confirm this supposition completely, because the intervention condition did not affect the relapse rate. Because families were allocated randomly to the two conditions, we may conclude that parents who received family intervention were better equipped to support their child, but it is hard to say how. In any case, it appears that in certain cases rehospitalisation or admissions to institutions for psychiatric patients can be prevented or delayed.
A number of studies showed that family intervention improved the social functioning of patients with schizophrenia (Falloon $\mathrm{et}$ al, 1987; Barrowclough \& Tarrier, 1990; Xiong et al, 1994). Falloon et al (1987) hypothesised that the problem-solving techniques of the family intervention caused a reduction in positive as well as in negative symptoms, so that patients were able to focus on their social condition. Leff et al (1989) suggested that social functioning depends on negative symptoms, which diminish more slowly than positive symptoms. This supposition was confirmed by Poque-Geile \& Harrow (1984) and by Bellack et al (1990). Although negative symptoms were not included in our study, a possible explanation for the absence of association between intervention condition and social functioning (i.e. structural activities for help from the family) might be that the family intervention was focused on the reduction of family stress and not particularly on social rehabilitation. However, in both intervention conditions the patients were given help with seeking education, employment and financial support.

\section{Severity of illness and social functioning}

For patients with a poorer course of the illness, whether as predicted by diagnosis at discharge or as indicated by the number of months with psychotic symptoms thereafter, social functioning was worse than for patients with a more favourable course of the illness. Possible explanations for this relationship were found in the literature.

Johnstone et al (1990) found that occupational functioning was better in patients who received a placebo than in patients on neuroleptic medication. Barrowclough $\&$ Tarrier (1990) found a negative association between dose of medication and social functioning. They argued that the tranquillising effect of neuroleptics could decrease the level of activities. In our study the influence of neuroleptic medication could not be assessed, because the LCS comprises only two global items about the prescription of medication. It is possible that patients with more months of psychotic symptoms took higher doses of neuroleptic medication, which could have affected their social functioning.

Bellack et al (1990) mentioned two possible hypotheses: impairment of social functioning as a consequence of negative symptoms or as a consequence of deficits in social skills. Although the association between negative symptoms and social functioning was demonstrated, support was found also for the social deficits hypothesis. No conclusions about the effect of negative symptoms can be drawn from our study, because these symptoms were not assessed for patients with chronic positive symptoms. However, patients with longer periods of positive symptoms functioned less well in the three areas of social functioning than patients with shorter periods of positive symptoms. Therefore, we cannot discount the role of positive symptoms.

\section{REFERENCES}

American Psychiatric Association (1987) Diagnostic and Statistical Manual of Mental Disorders (3rd edn, revised) (DSM-III-R). Washington, DC: APA.

Barrowclough, C. \& Tarrier, N. (1990) Social functioning in schizophrenic patients. I. The effects of expressed emotion and family intervention. Social Psychiatry and Psychiatric Epidemiology, 25, 125-129. 
Bellack, A. S., Morrison, R. L., Wixted, T. J., et al (1990) An analysis of social competence in schizophrenia. British Journal of Psychiatry, 156, 809-818.

Breier, A., Schreiber, J. L., Dyer, J., et al (1991) National Institute of Mental Health longitudinal study of chronic schizophrenia. Prognosis and predictors of outcome. Archives of General Psychiatry, 48, 239-246

Engelhardt, D. M. \& Rosen, B. (1976) Implications of drug treatment for the social rehabilitation of schizophrenic patients. Schizophrenia Bulletin, 2. 454-462.

Falloon, I. R. H., Boyd, J. L., McGill, C.W., et al (1982) Family management in the prevention of exacerbations of schizophrenia. New England Journal of Medicine, 306 |437-1440.

_, McGill, C. W., Boyd, J. L., et al (1987) Family management in the prevention of morbidity of schizophrenia: social outcome of a two-year longitudinal study. Psychological Medicine, I7, 59-66.

Johnstone, E. C., MacMillan, J. F., Frith, C. D., et al (1990) Further investigation of the predictors of outcome following first schizophrenic episodes. British Journal of Psychiatry, 157, 182-189.

Leff, J., Berkowitz, R., Shavit, N., et al (1989) A tria of family therapy $v$. a relatives group for schizophrenia. British Journal of Psychiatry, 154, 58-66.

Linszen, D., Dingemans, P., Van der Does, J.W., et a (1996) Treatment, expressed emotion and relapse in recent onset schizophrenic disorders. Psychological Medicine, 26, 333-342.

Mari, J. J. \& Streiner, D. L. (1994) An overview of family interventions and relapse on schizophrenia: meta-analysis of research findings. Psychological Medicine, 24, 565-578.

McGlashan, T. H. \& Johannessen, J. O. (1996)

Early detection and intervention with schizophrenia: rationale. Schizophrenia Bulletin, 22, 201-222.

Nuechterlein, K. H., Snyder, K. S., Dawson, M. E., et al (1986) Expressed emotion, fixed-dose fluphenazine decanoate maintenance, and relapse in recent-onset schizophrenia. Psychopharmacology Bulletin, 22, 633-639.

Poque-Geile, M. F. \& Harrow, M. (1984) Negative and positive symptoms in schizophrenia and depression: a followup. Schizophrenia Bulletin, 10, 37I-387.

Robinson, D., Woerner, M. G., Alvir, J. M. J., et al (1999) Predictors of relapse following response from a first episode of schizophrenia or schizoaffective disorder. Archives of General Psychiatry, 56, $24 I-247$.

Strauss, J. S. (1975) A comprehensive approach to psychiatric diagnosis. American Journal of Psychiatry, I32, 1193-1197.

_ \& Carpenter, W. T., Jr. (1974) The prediction of outcome in schizophrenia. II. Relationship between predictor and outcome variables: a report from the WHO International Pilot Study of Schizophrenia. Archives of General Psychiatry, 3I, 37-42.

\section{CLINICAL IMPLICATIONS}

- For patients with early-onset schizophrenia discontinuity of care may have a deleterious effect on the course of the illness. The results of the present study are congruent with the observation of others that interventions are effective as long as they are active.

- Family intervention for patients with schizophrenia, although not specifically focused on social rehabilitation, may diminish institutional care.

- Patients with schizophrenia who stay in the community after a short period in mental hospital need help in several areas. Interventions should focus not only on psychiatric symptoms but also on social rehabilitation.

\section{LIMITATIONS}

- The family intervention consisted of three ingredients - psychoeducation, training in communication skills and problem-solving techniques - and was contrasted with the standard intervention. The design of the study does not allow us to designate which part of the intervention was active in delaying rehospitalisation.

- Negative symptoms may have an effect on social functioning. With the Life Chart Schedule (LCS), negative symptoms were investigated only in a global way and only for patients without chronic positive symptoms.

- In this study medication compliance, an important predictor of the course of the illness, was not assessed adequately with the LCS.

MARIE E. LENIOR, MA, PETER M. A. J. DINGEMANS, PhD, DON H. LINSZEN, PhD, LIEUWE DE HAAN, MD, AART H. SCHENE, PhD, Academic Medical Center, University of Amsterdam, MFO Psychiatrie AMC/de Meren, The Netherlands

Correspondence: Marie E. Lenior, Psychiatric Center AMC, Tafelbergweg 25, II 05 BC Amsterdam, The Netherlands

(First received 7 September 2000, final revision 19 January 2001, accepted 23 January)

Susser, E., Finnerty, M., Mojtabai, R., et al (2000) Reliability of the Life Chart Schedule for assessment of the long-term course of schizophrenia. Schizophrenia Research, 42, 67-77.

Tarrier, N., Barrowclough, C., Vaughn, C., et al (1989) Community management of schizophrenia. A two-year follow-up of a behavioural intervention with families. British Journal of Psychiatry, 154, 625-628.

Vaughn, C. E. \& Leff, J. P. (1976) The measurement of expressed emotion in the families of psychiatric patients. British Journal of Social and Clinical Psychology, I5, 157-165.
Wiersma, D., Nienhuis, F. J., Slooff, C. J., et al (1998) Natural course of schizophrenic disorders: a 15-year followup of a Dutch incidence cohort. Schizophrenia Bulletin, 24, 75-85.

World Health Organization (1992) WHO Coordinated Multi-Center Study on the Course and Outcome of Schizophrenia. Geneva: WHO.

Xiong, W., Phillips, M. R., Hu, X., et al (1994) Family-based intervention for schizophrenic patients in China. A randomised controlled trial. British Journa of Psychiatry, 165, 239-247. 